\title{
The effect of fluoride toothpaste on root dentine demineralization progression: a pilot study*
}

\begin{abstract}
Juliana Nunes Botelho(a) Altair Antoninha Del Bel Cury ${ }^{(b)}$ Wander José da Silva ${ }^{(b)}$ Livia Maria Andaló Tenuta(a) Jaime Aparecido Cury ${ }^{(a)}$
\end{abstract}

(a) Department of Physiological Sciences, Piracicaba Dental School, University of Campinas - UNICAMP, Piracicaba, SP, Brazil.

(b) Department of Periodontology and Prosthodontics, Piracicaba Dental School, University of Campinas - UNICAMP, Piracicaba, SP, Brazil.

* Paper presented at the "Equity, Social Inclusion and Oral Health Promotion: Major Challenges" International Symposium, Held at the $18^{\text {th }}$ Congress of the Brazilian Association for Oral Health Promotion (Associação Brasileira de Odontologia de Promoção de Saúde - ABOPREV), April 2013, Bauru, SP, Brazil.

Declaration of Interests: The authors certify that they have no commercial or associative interest that represents a conflict of interest in connection with the manuscript.

Corresponding Author: Jaime Aparecido Cury

E-mail: jcury@fop.unicamp.br

htrp://dx.doi.org/10.1590/S1806-83242014.50000007 Epub Feb 12, 2014

Submitted: Aug 07, 2013 Accepted for publication: Nov 25, 2013 Last revision: Jan 08, 2014
Abstract: The anticaries effect of fluoride $(\mathrm{F})$ toothpaste containing $1100 \mu \mathrm{g} \mathrm{F} / \mathrm{g}$ in reducing enamel demineralization is well established, but its effect on dentine has not been extensively studied. Furthermore, it has been shown that toothpaste containing a high $\mathrm{F}$ concentration is necessary to remineralize root dentine lesions, suggesting that a $1100 \mu \mathrm{g}$ F/g concentration might not be high enough to reduce root dentine demineralization, particularly when dentine is subjected to a high cariogenic challenge. Thus, the aim of this pilot study was to evaluate in situ the effect of $\mathrm{F}$ toothpaste, at a concentration of $1100 \mu \mathrm{g} \mathrm{F} / \mathrm{g}$, on dentine demineralization. In a crossover and double-blind study, conducted in two phases of 14 days, six volunteers wore a palatal appliance containing four slabs of bovine root dentine whose surface hardness $(\mathrm{SH})$ was previously determined and to which a $10 \%$ sucrose solution was applied extra-orally $8 \times /$ day. Volunteers used a non-F toothpaste (negative control) or $\mathrm{F}$ toothpaste $\left(1100 \mu \mathrm{g} \mathrm{F} / \mathrm{g}, \mathrm{NaF} / \mathrm{SiO}_{2}\right)$ three times a day. On the $10^{\text {th }}$ and $14^{\text {th }}$ days of each phase, two slabs were collected and $\mathrm{SH}$ was determined again. Dentine demineralization was assessed as percentage of SH loss (\%SHL). The effect of toothpaste was significant, showing lower $\%$ SHL for the $\mathrm{F}$ toothpaste group $(42.0 \pm 9.7)$ compared to the non-F group $(62.0 \pm 6.4 ; p<0.0001)$, but the effect of time was not significant $(p>0.05)$. This pilot study suggests that $\mathrm{F}$ toothpaste at $1100 \mu \mathrm{g} \mathrm{F} / \mathrm{g}$ is able to decrease dentine caries even under a high cariogenic challenge of biofilm accumulation and sugar exposure.

Descriptors: Dentin; Sucrose; Fluorides; Biofilms; Dental Caries.

\section{Introduction}

Over the last decades, the significant increase in longevity and the reduction in the prevalence of enamel caries around the world have raised the concern about caries prevention in the elderly, who will have a large amount of root dentine exposed in their mouths. Therefore, since dentine is more susceptible to caries than enamel, ${ }^{1,2}$ the concern about prevention of root caries is increasing. ${ }^{3}$

Fluoride $(\mathrm{F})$ toothpaste is widely used and it has been considered responsible for the caries decline that occurred in developed countries in the $1980 \mathrm{~s}^{4}$ and in developing ones in the 1990s. ${ }^{5}$ The anticaries effect of $\mathrm{F}$ toothpaste containing $1100 \mu \mathrm{g} \mathrm{F} / \mathrm{g}$ (ppm F) in reducing enamel caries is well established, ${ }^{6,7}$ but its effect on dentine has not been extensively 
studied. ${ }^{8,9}$

Furthermore, it has been shown that toothpaste containing a high $\mathrm{F}$ concentration is necessary to remineralize root dentine lesions, ${ }^{10-13}$ and the effect of $\mathrm{F}$ in decreasing demineralization has been little explored. ${ }^{14-16}$ Considering that the critical $\mathrm{pH}$ for dentine dissolution is about 6.8 to 6.0 , a slight decrease in the $\mathrm{pH}$ of the biofilm fluid will lead to demineralization. ${ }^{17}$ However, if $\mathrm{F}$ is present in biofilm fluid and the $\mathrm{pH}$ is not lower than 4.5 , fluorapatite will be formed as long as hydroxyapatite is dissolved. ${ }^{18}$ This reduction in demineralization is not able to avoid loss of part of the minerals, but a higher availability of $\mathrm{F}$ might have a better effect. Thus, a concentration of $1100 \mu \mathrm{g}$ F/g might not be high enough to reduce dentine demineralization if this dental tissue is exposed to a high cariogenic challenge by biofilm accumulation and sugar exposure over time.

The aim of this pilot study was thus to evaluate in situ the effect of $1100 \mu \mathrm{g} \mathrm{F/g}$ toothpaste on the progression of root dentine demineralization.

\section{Methodology Ethical aspects and volunteers}

This pilot study was approved by the Research and Ethics Committee of the Piracicaba Dental School (protocol no. 104/2011), and volunteers signed an informed, written consent to participate (Resolution no. 196 of the Conselho Nacional de Saúde - CNS, Ministério da Saúde - MS, Brasília, Brazil, 10/03/1996).

Six volunteers (21-35 years old), who fulfilled inclusion criteria (normal salivary flow rate, good general and oral health with no active caries lesions or periodontal treatment needs, ability to comply with the experimental protocol, not having used antibiotics during the 2 months prior to the study and not using fixed or removable orthodontic devices) were selected to participate in the study. The volunteers selected had a mean decayed, missing and filled tooth surfaces index (DMFS) of $9.5 \pm 10.03$.

\section{Experimental design}

The study used a double-blind, crossover design, and was conducted in two phases of 14 days each, during which six volunteers wore palatal appliances containing four slabs of bovine root dentine with known surface hardness (SH). ${ }^{19}$ A $10 \%$ sucrose solution, prepared by the researchers, was provided for the volunteers. This solution was applied extraorally to the slabs eight times per day as a cariogenic challenge. The volunteers brushed their teeth and the appliance with a non-F toothpaste (negative control) or F toothpaste (1100 $\mu \mathrm{g} \mathrm{F/g,} \mathrm{NaF/silica-based)}$ three times a day (the dentifrice formulations were prepared by Colgate/Palmolive, São Bernardo do Campo, Brazil). On the $10^{\text {th }}$ and $14^{\text {th }}$ days of each phase, two slabs were collected and evaluated for mineral loss by SH. The sequence of toothpaste used by each volunteer was randomly assigned and, after the two phases, all volunteers had undergone the two treatments. For all determinations, the volunteer was considered the experimental unit.

\section{Dentine slabs and palatal appliance preparation}

The root dentine slabs $(4 \times 4 \times 2 \mathrm{~mm})$ were prepared from bovine incisor teeth as previously described. ${ }^{19}$ The artificial saliva, prepared by the researchers, contained $1.5 \mathrm{mM} \mathrm{Ca}, 0.9 \mathrm{mM} \mathrm{P}$, $150 \mathrm{mM} \mathrm{KCl}, 0.1 \mathrm{M}$ Tris, $\mathrm{pH}$ 7.0. ${ }^{20}$ The slabs were immersed in this solution for $24 \mathrm{~h}$ to allow dentine mineral gain and minimize further ionic changes when exposed to saliva in situ. ${ }^{21}$ The $\mathrm{SH}$ of the dentine slabs was determined by making 3 indentations, spaced $100 \mu \mathrm{m}$ apart, using a Knoop indenter with a $5 \mathrm{~g}$ load for $5 \mathrm{~s}$ and a microhardness tester coupled to FM-ARS 900 software (Future-Tech Corp., Kawasaki, Japan). Before performing the dentine hardness measurements, the slabs were allowed to dry for at least 30 minutes to minimize the interference of dentine dehydration with the measurements. ${ }^{8}$ Forty-eight slabs with a mean hardness of $43.2 \mathrm{~kg} / \mathrm{mm}^{2}$ (SD 4.4) were selected and were randomly divided into two groups of 24 specimens each, according to the toothpaste treatments. Acrylic palatal appliances were made for each volunteer with four positions (two on each side of the appliance) for slabs. Plastic meshes were fixed over the cavities to protect the dentine slab surfaces from mechanical attrition, leaving a $1 \mathrm{~mm}$ space for biofilm accumulation (see Hara et al. ${ }^{19}$ for details). 


\section{Treatments}

During the lead-in and washout periods of 7 days each, the volunteers brushed their teeth with non-F toothpaste. Volunteers lived in an optimally fluoridated city $(0.6-0.8 \mathrm{mg} / \mathrm{F}$ for the region) and received instructions as previously described. ${ }^{22}$ Considering the crossover design of this study, no restriction was made with regards to the volunteers' diet, except that they were instructed to avoid F-rich foods containing bioavailable $\mathrm{F}$, such as tea. They also received oral and written information to refrain from using any antibacterial substance.

To provide a cariogenic challenge during the 14 days of each experimental phase, 8 times per day (8:00, 9:00, 10:00, 11:00, 14:00, 15:30, 17:00, 19:00 h), volunteers removed the device from the oral cavity and applied one drop of the $10 \%$ sucrose solution on each dental slab. After 5 minutes, the device was re-inserted in the mouth.

Throughout the experiment, volunteers brushed their teeth and the device after the main mealtimes, 3 times a day $(7: 30,12: 30,20: 00 \mathrm{~h})$, with the toothpaste assigned for each phase. The device was removed and volunteers brushed their teeth and the appliance with the assigned toothpaste, taking care to only apply the slurry formed on the slab area of the device. The device was then washed gently in tap water and re-inserted in the mouth. The volunteers were instructed to wear the intraoral devices throughout the 14 experimental days, removing them only for oral hygiene and during meals.

\section{Dentine analysis}

On the $10^{\text {th }}$ and $14^{\text {th }}$ days of each phase, two slabs were removed from the devices and the $\mathrm{SH}$ was measured again. One row of three adjacent indentations spaced $100 \mu \mathrm{m}$ apart was made $100 \mu \mathrm{m}$ from the three baseline measurements. The mean values of the three baseline indentations and the three measurements after treatments were then averaged, and the percentage of SH loss (\%SHL) was calculated according to the following equation:

$\%$ SH $=$ (baseline $S H-S H$ after in situ test $) \times$ 100/baseline $\mathrm{SH}$
$\mathrm{SH}$ loss was used as an indicator of dentine demineralization. ${ }^{8,22}$ The results of the two dentine slabs for each volunteer subjected to each treatment were averaged and analyzed statistically $(n=6)$. The $\mathrm{SH}$ was used to estimate demineralization of root dentine because there is a high correlation with mineral loss assessed by transverse microradiography. ${ }^{8}$

\section{Statistical analysis}

A $2 \times 2$ factorial was considered for the statistical analyses, and the factors evaluated were:

- toothpaste at 2 levels (fluoridated and non-fluoridated) and

- time at 2 levels (10 ${ }^{\text {th }}$ and $14^{\text {th }}$ days).

Volunteers were considered statistical blocks. The assumption of equality of variances and normal distribution of errors was checked. The variables were analyzed by two-way analysis of variance (ANOVA). The analysis was conducted with SAS 9.0 software (SAS Institute, Cary, USA), with a significance level fixed at $p<0.05$.

\section{Results}

The effect of the dentifrice factor was significant $(p<0.001$, Figure 1), showing lower \%SHL for the group treated with $\mathrm{F}$ toothpaste $(42.0 \pm 9.7) \mathrm{com}-$ pared with the control $(62.0 \pm 6.4)$ group. However, the effect of time was not significant $(p>0.05)$.

\section{Discussion}

The effect of $\mathrm{F}$ toothpaste in reducing enamel caries, provided the concentration is $1000 \mu \mathrm{g} \mathrm{F} / \mathrm{g}$ or higher, is based on evidence. ${ }^{7}$ Considering that dentine is more caries-susceptible and demineralizes 2.5 times faster than enamel, ${ }^{23}$ it is possible that a concentration of $1100 \mu \mathrm{g}$ F/g might not be high enough to control root dentine caries. In fact, there is some evidence that a toothpaste containing $5000 \mu \mathrm{g} \mathrm{F} / \mathrm{g}$ is more effective in repairing root dentine caries than one containing $1100 \mu \mathrm{g}$ F/g. ${ }^{11,12}$

In the present in situ study, simulating in vivo conditions of biofilm accumulation and high exposure to sucrose, the toothpaste containing $1100 \mu \mathrm{g}$ F/g significantly reduced $(p<0.05)$ root dentine demineralization compared with the placebo denti- 
Figure 1 - Means of dentine surface hardness loss according to toothpaste treatment (bars denote standard deviations; $\mathrm{n}=6$;

FT: fluoride toothpaste; NFT: nonfluoride toothpaste; ${ }^{*}$ statistically significant difference between toothpaste treatments $[p<0.001]$ for the different time points evaluated)

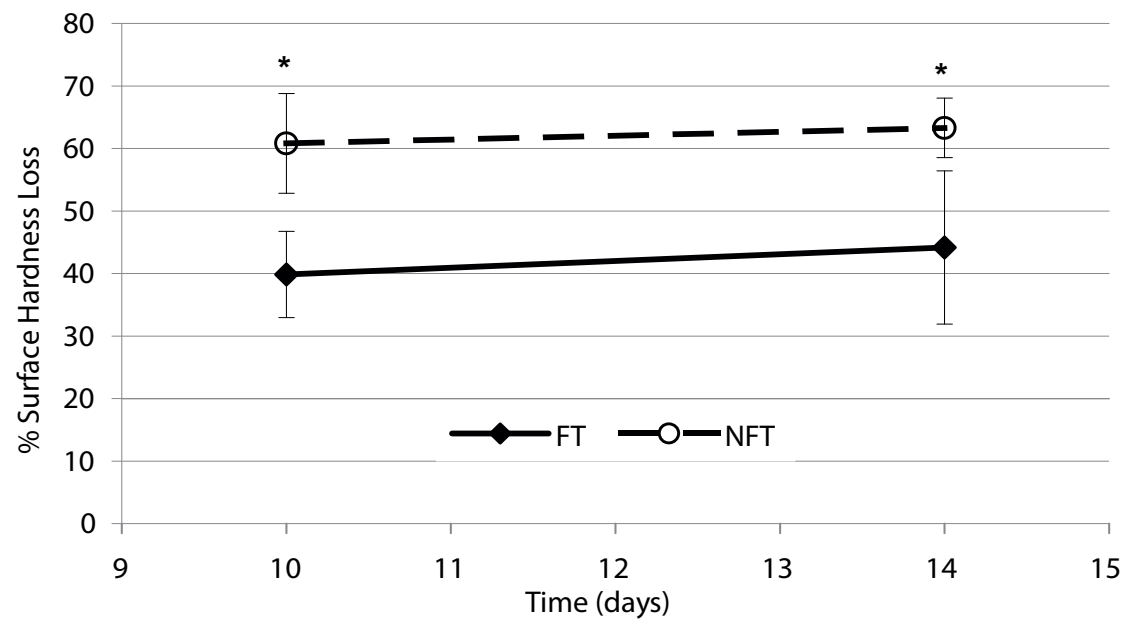

frice. The $32 \%$ of reduction found is in agreement with in vitro findings, ${ }^{24}$ but was lower than that found previously in situ (47\%), ${ }^{8}$ which might be explained by differences in the duration of both studies.

The effect of the $1100 \mu \mathrm{g}$ F/g toothpaste in reducing root dentine demineralization by $32 \%$ was accomplished by using toothpaste 3 times/day. This value is very close to that found by Kusano et al., ${ }^{9}$ when a $1100 \mu \mathrm{g}$ F/g toothpaste was used only once a day at night. The data suggest that when brushing at night is performed daily, the other two brushing episodes (in the morning and after lunch) are less important. The percentage of reduction of dentine demineralization found in the present study was lower than the $67 \%$ reduction in root caries found in vivo by Jensen and Kohout ${ }^{25}$ with elderly people living in a non-fluoridated community. The high cariogenic challenge of our in situ study and the effect of optimally fluoridated water, attenuating the strength of F-toothpaste use, may partially explain the smaller effect observed.

We also evaluated the effect of time and tested whether the experimental phases lasting for 10 or 14 days would demonstrate caries progression. Nevertheless, our findings showed that the \%SHL was similar in both periods for the $\mathrm{F}$ toothpaste and control groups. This may be explained by the fact that dentine demineralizes faster than enamel, and that demineralization is very fast in the first week and progresses slower after that, as a result of the presence of a demineralized organic matrix acting as a barrier between biofilm and the dentine surface. ${ }^{23}$
In this context, the period between the two evaluations might not be long enough to show the possible differences in $\mathrm{SH}$ or, perhaps, progression of the lesion could not be measured because the outer surface layer may have reached equilibrium with the biofilm fluids and progression would be observed in the body of the lesion.

These results showed that although the $1100 \mu \mathrm{g}$ F/g toothpaste could not avoid dentine demineralization, it was able to reduce it even under a high cariogenic challenge of biofilm accumulation and sugar exposure. Moreover, this is a pilot study with six volunteers, and other in situ studies with more volunteers may be necessary, followed by clinical trials with elderly populations to assess the initiation and progression of dentine caries lesions while using toothpastes with different $\mathrm{F}$ concentrations.

\section{Conclusion}

In summary, this pilot in situ study suggests that a $1100 \mu \mathrm{g} \mathrm{F/g}$ toothpaste is able to decrease root dentine caries.

\section{Acknowledgements}

The authors would like to thank the volunteers who took part in this study, and Colgate/Palmolive (São Bernardo do Campo, Brazil) for kindly providing the toothpaste formulations used. This research has been partly funded by Conselho $\mathrm{Na}$ cional de Pesquisa e Desenvolvimento Científico e Tecnológico - CNPq grants 475178/2011-4 and 305310/2011-9 to J.A.C. The first author received a 
scholarship from Conselho Nacional de Pesquisa e Desenvolvimento Científico e Tecnológico - CNPq (140372/2010-5) during her graduate course in Dentistry at the Piracicaba Dental School, University of Campinas - UNICAMP. Preliminary reports were

\section{References}

1. Nyvad B, Fejerskov O. Root surface caries: clinical, histopathological and microbiological features and clinical implications. Int Dent J. 1982 Dec;32(4):311-26.

2. Wefel JS. Root caries histopathology and chemistry. Am J Dent. 1994 Oct;7(5):261-5.

3. Curzon MEJ, Preston AJ. Risk groups: nursing bottle caries/ caries in the elderly. Caries Res. 2004 Jan;38(Suppl 1):24-33.

4. Bratthall D, Hänsel-Petersson G, Sundberg H. Reasons for the caries decline: what do the experts believe?. Eur J Oral Sci. 1996 Aug;104(4 (Pt 2)):416-22.

5. Cury JA, Tenuta LMA, Ribeiro CCC, Paes Leme AF. The importance of fluoride dentifrices to the current dental caries prevalence in Brazil. Braz Dent J. 2004;15(3):167-74.

6. Marinho VC, Higgins JP, Sheiham A, Logan S. Fluoride toothpastes for preventing dental caries in children and adolescents. Cochrane Database Syst Rev. 2003;(1):CD002278.

7. Walsh T, Worthington HV, Glenny AM, Appelbe P, Marinho VC, Shi X. Fluoride toothpastes of different concentrations for preventing dental caries in children and adolescents. Cochrane Database Syst Rev. 2010 Jan 20;(1):CD007868.

8. Vale GC, Tabchoury CPM, Del Bel Cury AA, Tenuta LMA, ten Cate JM, Cury JA. APF and dentifrice effect on root dentine demineralization and biofilm. J Dent Res. 2011 Jan;90(1):77-81.

9. Kusano SC, Tenuta LMA, Del Bel Cury AA, Cury JA. Timing of fluoride toothpaste use and enamel-dentine demineralization. Braz Oral Res. 2011 Sep-Oct;25(5):383-7.

10. Lynch E, Baysan A, Ellwood R, Davies R, Petersson L, Borsboom P. Effectiveness of two fluoride dentifrices to arrest root carious lesions. Am J Dent. 2000 Aug;13(4):218-20.

11. Baysan A, Lynch E, Ellwood R, Davies R, Petersson L, Borsboom $P$. Reversal of primary root caries using dentifrices containing 5,000 and 1,100 ppm fluoride. Caries Res. 2001 JanFeb;35(1):41-6.

12. Ekstrand K, Martignon S, Holm-Pedersen P. Development and evaluation of two root caries controlling programmes for home-based frail people older than 75 years. Gerodontology. 2008 Jun;25(2):67-75.

13. Nordström A, Birkhed D. Preventive effect of high-fluoride dentifrice $(5,000 \mathrm{ppm})$ in caries-active adolescents: a 2-year clinical trial. Caries Res. 2010;44(3):323-31. presented at the $91^{\text {st }}$ General Session of the International Association for Dental Research - IADR (Seattle, WA, USA, 2013) and the $18^{\text {th }}$ Congress of the Associação Brasileira de Odontologia de Promoção de Saúde - ABOPREV (Bauru, Brazil, 2013).

14. Dunipace AJ, Zhang W, Beiswanger AJ, Stookey GK. An in vitro model for studying the efficacy of fluoride dentifrices in preventing root caries. Caries Res. 1994;28(5):315-21.

15. Featherstone JD. Fluoride, remineralization and root caries. Am J Dent. 1994 Oct;7(5):271-4.

16. Herkströter FM, Witjes M, Arends J. Demineralization of human dentine compared with enamel in a $\mathrm{pH}$-cycling apparatus with a constant composition during de- and remineralization periods. Caries Res. 1991;25(5):317-22.

17. Hoppenbrouwers PMM, Driessens FCM, Borggreven JMPM. The vulnerability of unexposed human dental roots to demineralization. J Dent Res. 1986 Jul;65(7):955-8.

18. ten Cate JM, Larsen MJ, Pearce EIF FO. Chemical interactions between the tooth and oral fluids. In: Fejerskov O, Kidd EAM, editors. Dental caries: the disease and its clinical management. Copenhagen: Blackwell Munksgaard; 2003. p. 49-69.

19. Hara AT, Queiroz CS, Paes Leme AF, Serra MC, Cury JA. Caries progression and inhibition in human and bovine root dentine in situ. Caries Res. 2003 Sep-Oct;37(5):339-44.

20. Delbem ACB, Cury JA. Effect of application time of APF and $\mathrm{NaF}$ gels on microhardness and fluoride uptake of in vitro enamel caries. Am J Dent. 2002 Jun;15(3):169-72.

21. Aires CP, Tabchoury CPM, Del Bel Cury AA, Cury JA. Effect of a lactose-containing sweetener on root dentine demineralization in situ. Caries Res. 2002 May-Jun;36(3):167-9.

22. Cury JA, Rebelo MA, Del Bel Cury AA, Derbyshire MT, Tabchoury CP. Biochemical composition and cariogenicity of dental plaque formed in the presence of sucrose or glucose and fructose. Caries Res. 2000 Nov-Dec;34(6):491-7.

23. Ögaard B, Rölla G, Arends J. In vivo progress of enamel and root surface lesions under plaque as a function of time. Caries Res. 1988;22(5):302-5.

24. ten Cate JM, Buijs MJ, Damen JJ. pH-cycling of enamel and dentine lesions in the presence of low concentrations of fluoride. Eur J Oral Sci. 1995 Dec;103(6):362-7.

25. Jensen ME, Kohout F. The effect of a fluoridated dentifrice on root and coronal caries in an older adult population. J Am Dent Assoc. 1988 Dec;117(7):829-32. 